\title{
BMJ Global Health Health system governance and the UHC agenda: key learnings from the COVID-19 pandemic
}

\author{
Carmen Huckel Schneider
}

To cite: Huckel Schneider C Health system governance and the UHC agenda: key learnings from the COVID-19 pandemic. BMJ Global Health 2021;6:e06519. doi:10.1136/ bmjgh-2021-006519

Received 4 June 2021 Accepted 5 June 2021
Check for updates

(c) Author(s) (or their employer(s)) 2021. Re-use permitted under CC BY-NC. No commercial re-use. See rights and permissions. Published by BMJ.

Menzies Centre for Health Policy and Economics, Sydney School of Public Health, Faculty of Medicine and Health, The University of Sydney, Sydney, New South Wales, Australia

Correspondence to Dr Carmen Huckel Schneider; carmen.huckelschneider@ sydney.edu.au
Immediately prior to the emergence of SARS-CoV-2 and the ensuing global COVID-19 pandemic, global health policy experienced a peak in political attention for Universal Health Coverage (UHC) as a key paradigm to strengthen health systems and achieve global health. As a set of health policy goals, UHC emphasises the responsibility of governments to enable broad equitable access to quality health services and strengthen the health system pillars that are required to maintain them. The 2019 United Nations (UN) General Assembly Political Declaration of the High-level Meeting on Universal Health Coverage was passed following months of debate and negotiation in October 2019, just weeks before the first known cases of SARS-CoV-2 emerged. ${ }^{1}$

The COVID-19 pandemic has arguably added further potency to the call for attention on strengthening health systems and achieving UHC. ${ }^{2}$ The worst effects of the pandemic arose in situations where health systems became overwhelmed, as the spread of disease increased at a rate faster than public health systems could trace it, and numbers of severe cases exceeded the capacity of health services to treat it.

\section{UHC AS A GLOBAL HEALTH POLICY PARADIGM}

UHC gained momentum as a unifying, broad and systems-based approach in the 2010s, although its origins can be traced back to movements a century earlier and the waxing and waning of health systems approaches to global health since. ${ }^{3}$ The 2019 declaration drew out a comprehensive and wide-ranging list of key principles that should underpin achieving UHC with a particular focus on service accessibility; equitable distribution of essential medicines and technologies; increases in overall health funding; protection from financial burden; the rights of vulnerable groups; growth of the health workforce and importantly, strong health system governance. ${ }^{4}$

Despite this comprehensive list of key principles, a 2020 survey of key stakeholders in countries party to the declaration undertaken by UHC 2020 found that many states were "unclear about what constitutes a UHC commitment $^{5}$ and what actions government should be taking towards it. UHC has achieved success as a movement and conceptual framework, but the UN declaration can be best seen as a launching pad for the next stage in its development - a stage which will require building a stronger evidence base for the operationalisation of UHC's key principles. $^{6}$

COVID-19 has presented a wealth of experience and as such lessons for health systems strengthening-particularly in terms of health systems governance. Despite being frequently cited as a key pillar of strong health systems, governance and leadership in particular has often proven difficult to conceptualise, even harder to measure and as a consequence an elusive target for policy improvement. ${ }^{7}$ In a recent focused edition of this journal, Bruno Meessen found that while the literature on health system governance is growing, the empirical agenda is progressing only slowly. ${ }^{8}$

Health system governance can be defined as the structures and institutions that determine the roles and responsibilities of, and relationships between, various health system actors in taking and enacting policy decisions. Experiences around the world as health systems were faced with the COVID-19 pandemic brought to light the essential nature of four sets of relationships at the core of health system governance that have proven key to resilience and performance. Lessons from these experiences can help to build the missing empirical basis of health system governance. 


\section{First: Relationships between public health, primary,} secondary and tertiary health services

During the COVID-19 pandemic, health systems needed to monitor outbreaks and provide new services, in rapid time, on a large scale. The ability of health systems to surge in capacity and deploy technologies and workforce proved critical. The organisation of health services throughout health systems determined this capacity, in particular the extent to which access to COVID-19 related services was eased (single point of contact and free of upfront costs), trained workforce (clinical and administrative) was able to be redeployed, and diagnostic and treatment services were able to be coordinated.

Vital factors included where in the system key functions of public health were located (who undertook contact tracing, who held responsibility for communicating public health messaging); how pathology was integrated into disease surveillance and reporting systems (including data transfer); and the how the place of primary care physicians-as system entry points-was managed. Most countries struggled to organise contacttracing efforts and fully integrate primary health services into COVID-19 responses due to a mismatch between the workforce, resources and skills required, and the administrative and financing models that located these functions and services in effectively separate systems. ${ }^{9}$

\section{Second: Relationships between central and local administrative levels}

Key case studies in the responses of centralised and devolved government systems to the pandemic have consistently found that political and public discourse favoured strong centralised action and decision making in the first half of 2020, and this often led to new and innovative ways of working. ${ }^{10}$ However, as the pandemic progressed the difficulties of compromise in devolved systems re-emerged as they struggled to implement cohesive national action once the pandemic moved into a management phase with differential effects across regions. Rivalries ensued between administrative units, particularly those governed by rival political parties, and much needed cooperation during critical times slowed. Centralised systems on the other hand also faced difficulties establishing and implementing easily accessible test regimes and contact-tracing which function best with localised coordination across health service provider types. ${ }^{11}$ The Organisation for Economic Co-operation and Development (OECD) found that a comparison of federalised and non-federalised health systems in the pandemic did not advantage one or the other on the whole, but did highlight the importance of clear roles, responsibilities, capabilities and, importantly, rules of deliberation, compromise and decision-making between levels of government and health administration. ${ }^{12}$
Third: Relationships between evidence production, expertise, technical advisory and decision makers

Decision makers relied on evidence synthesis and expert advice to underpin policy decisions, ranging from interventions such as wearing face masks, curfews, border closures to economic stimulus and vaccine allocations. The extent to which such evidence can be successfully gathered and used has relied on two key factors during the COVID-19 pandemic. The first is an institutional infrastructure for gathering evidence, synthesising it and interpreting it into technical advice. Systems of public health surveillance needed to be time efficient and accurate with efficient data transfer from local to central reporting units and ultimately to established institutions for the analysis and communication of the meaning of these data. This function was dispersed in various combinations in different countries between established or ad hoc centres for disease surveillance and standing technical advisory committees.

The second key factor required to maintain an effective evidence-based response is sound relationships between these institutions, technical experts and decision makers, in particular leadership in government. These relationships require a particularly high level of maturity to steer the course during high-stakes decisions, especially as there was frequently fierce debate where evidence was still emerging or equivocal. Many countries struggled with the need to be able to accept the nature of such debate, respect the independence of health research institutions, and be willing to fully deliberate and take decisions based on technical advice. ${ }^{13}$

\section{Fourth: Relationships between public and private sectors in health systems}

Most health systems are comprised of a mix of public and private actors; from the providers of health services to health insurance; from the information technology platforms that underpin medical records to the research, development and application of diagnostics, therapeutics and vaccines. The pandemic has demonstrated the need to optimise the relationships between the public and private actors that now underpin the fundamental functioning of health systems ${ }^{14}$ that must be organised to enable health systems that progress towards health equity and improvement. COVID-19 has demonstrated the extent to which poor governance of these relationships can have severe consequences during times of crisis. For example, regions that experienced acute COVID-19 outbreaks required surge capacity in often unprofitable preventative, critical and intensive care services. Health systems became overwhelmed where drivers of health system funding had depleted these services and isolated both public and private sectors from a whole-of-system crisis response. $^{15}$

The pursuit of suitable vaccines to fight the COVID-19 pandemic also exemplified the opportunities and challenges of optimising relationships between public and private actors for health. The complex patterns of revenue 
raising, licensing and purchasing have highlighted the truly incremental and global nature of medical research, while the ongoing challenges of manufacturing, procurement and distribution demonstrate the co-dependence of public and private sectors.

\section{CONCLUSION}

These four key sets of relationships, as key facets of health system governance, proved key to resilience in the pandemic and require ongoing attention. Optimising these relationships is essential to ensure that health systems progress towards health equity and improvement.

The COVID-19 pandemic has served to highlight the importance of whole-of-systems approaches to global health and improving health system governance in particular. Framing health governance as the organisation of relationships between systems parts can help guide the development of an empirical basis for health system improvement-and ultimately the further development of the UHC agenda.

Acknowledgements This editorial follows a contribution to the Reform for Resilience Commission, an international initiative that seeks to frame practical recommendations for a post-COVID world for policymakers across governments and international agencies.

Contributors The editorial is the sole work of CHS.

Funding The authors have not declared a specific grant for this research from any funding agency in the public, commercial or not-for-profit sectors.

Competing interests None declared.

Patient consent for publication Not required.

Provenance and peer review Commissioned; internally peer reviewed.

Data availability statement All data relevant to the study are included in the article.

Open access This is an open access article distributed in accordance with the Creative Commons Attribution Non Commercial (CC BY-NC 4.0) license, which permits others to distribute, remix, adapt, build upon this work non-commercially, and license their derivative works on different terms, provided the original work is properly cited, appropriate credit is given, any changes made indicated, and the use is non-commercial. See: http://creativecommons.org/licenses/by-nc/4.0/.

\section{ORCID iD}

Carmen Huckel Schneider http://orcid.org/0000-0002-7493-3589

\section{REFERENCES}

1 World Health Organisation,. Origin of SARS-CoV-2. Geneva: World Health Organisation, 2020.

2 Tangcharoensathien V, Mills A, Patcharanarumol W, et al. Universal health coverage: time to deliver on political promises. Bull World Health Organ 2020;98:78

3 Gorsky M, Sirrs C. The Rise and Fall of "Universal Health Coverage" as a Goal of International Health Politics, 1925-1952. Am J Public Health 2018;108:334-42.

4 Bloom G, Katsuma Y, Rao KD, et al. Next steps towards universal health coverage call for global leadership. BMJ 2019;365:12107.

5 UHC 2030. State of commitment to universal health coverage: synthesis 2020. UHC 2030, 2020.

6 Wright S, Mabejane R. The 2019 un high-level meeting on universal health coverage. The Lancet 2019;393:1931.

7 Abimbola S. Health system governance: a triangle of rules. BMJ Glob Health 2020;5:e003598.

8 Meessen B. Health system governance: welcoming the reboot. BMJ Glob Health 2020;5:e002404.

9 Lewis D. Why many countries failed at COVID contact-tracing - but some got it right. Nature 2020;588:384-7.

10 Palermo F. Devolution and COVID-19: Italy: did the virus infect the regional system? Revista" Cuadernos Manuel Giménez Abad" 2020;19:26-7.

11 Czauderna Jet al. Covid-19 test and trace scandal-it's not too late to change the story. BMJ Opinion 2021.

12 Biase Pd, Dougherty S. Federalism and public health decentralisation in the time of COVID-19, 2021.

13 Dissanayake R. Evidence-Based decision making during COVID-19: how to navigate extreme uncertainty and urgency, in commentary and analysis. Center for Global Development, 2020.

14 Clarke D, Doerr S, Hunter M, et al. The private sector and universal health coverage. Bull World Health Organ 2019;97:434-5.

15 Faggioni MP, González-Melado FJ, Di Pietro ML. National health system cuts and triage decisions during the COVID-19 pandemic in Italy and Spain: ethical implications. J Med Ethics 2021;47:300-7. 